\title{
Jerónimo López: un conquistador entre la reivindicación y el arbitrismo
}

Isabel Arenas Frutos

Departamento de Historia II, Universidad de Huelva

En el presente trabajo analizamos la figura de "uno de los primeros conquistadores", como él mismo se autodenomina, al que incluimos dentro de esa línea protoarbitrista que iniciará su escalada a partir de mediados del siglo XVI, ya que refleja en su amplia y continuada secuencia epistolar características de los seguidores de dicha escuela político-económica. Notificó sobre innumerables asuntos, problemas y personajes que consideró dignos de mención, tratando además de dar los "remedios y soluciones" que creía convenientes para ello, algo tan típico dentro de esa tendencia.

La tendencia conocida como "arbitrismo" —importada de Flandes e Italia- inició su gran escalada a partir de mediados del siglo XVI, creciendo y adquiriendo toda su fuerza en la posterior centuria, para declinar visiblemente en el XVIII. ${ }^{1}$

En dos cosas se manifiesta el carácter atrevido y jactancioso de los arbitristas: en su presunción de anunciar al mundo ruidosas verdades y de pasar por mensajeros de Dios para mostrar el camino de la redención, y en su vanidad de curar de un golpe y con un solo remedio todos los males de la república, siendo así que suelen ser muchos, diversos y nacidos de muy distintas causas. $^{2}$

Siempre es interesante rastrear estas manifestaciones iniciales del arbitrismo allende el Atlántico, con esos personajes que podríamos denominar "protoarbitristas" al manifestar en sus escritos peculiaridades de los continuadores de dicho sistema. Éstos, además de plantear reiteradamente diferentes peticiones particulares y redactar innumerables cartas y memoriales, tan típicos de la época, comienzan a recomendar modificaciones y proyectos - ahí se centra nuestro interés-, en pro de remedios eficaces para una pronta disposición y mejora de aquellas provincias. Dentro de esa doble línea, de reclamaciones y propuestas, podemos considerar incluido a nuestro protagonista.

1 Colmeiro, Manuel: Historia de la economía política en España. 2 vols. Biblioteca Política Taurus. Madrid, 1965, T. II, pág. 1178.

2 Ídem. 
Para la realización de este trabajo, hemos contado con los fondos documentales del Archivo General de Indias de Sevilla, depositario de una amplia secuencia epistolar de Jerónimo López, uno "de los primeros conquistadores", ${ }^{3}$ como él mismo se autodefinió, además de diferentes textos paleográficos, cuyos originales proceden de México.

\section{Esbozo biográfico}

Aunque tanto en su testamento, otorgado en la ciudad de México el 18 de mayo de 1549 , como en su relación de méritos y servicios, ${ }^{4}$ indicaba que era natural de la villa de El Pedroso (Sevilla), ${ }^{5}$ coincidiendo en ello los autores consultados, ${ }^{6}$ su primogénito homónimo "el Mozo", también en su última voluntad, señalaba que su progenitor nació en Cáceres (Extremadura), —en torno a $1488 —,{ }^{7}$ y que muy niño pasó con sus padres a radicarse a dicha villa del Pedroso, y de allí se trasladaron a Sevilla (colación de Santa María). ${ }^{8}$ Fueron sus padres Antón López de Viar — hijodalgo- 9 y Elvira Fernández de la Cuesta y era nieto de Garci López de Viar y de Elvira Fernández de la Parra, contando como quinto abuelo al comendador Garci López de Viar.

En esta última ciudad, "en tiempo del Rey Católico", cuando oyó pregonar "en las gradas...con sole(m)nidad de trompetas" que los que se decidiesen a poblar las Indias, obtendrían pasaje gratis, además de otras ayudas y favores (ganados, rentas perpetuas...), se le despertó el interés por las nuevas tierras, ${ }^{10}$ marchando a Cuba en 1520 , en un grupo de unas cien per-

3 Así lo atestigua una y otra vez en sus escritos.

4 Fernández del Castillo, Francisco (versión paleográfica, notas e índice alfabético): “Tres conquistadores y pobladores de la Nueva España”. Archivo General de la Nación. 2 vols. T. XII. México, 1927, págs. 227-246 y 253-257.

5 De entre todos éstos, sólo citaremos dos, por ser en los que suelen basarse la mayoría de las obras: Álvarez, Víctor M.: Diccionario de conquistadores. 2 vols. México, 1975. T. II, pág. 303 e Icaza, Francisco A. de: Diccionario autobiográfico de conquistadores y pobladores de Nueva España. 2 vols. Madrid, 1923. Vol. I, pág. 88.

6 Fernández del Castillo, Francisco: "Tres conquistadores...”, pág. 228.

7 En 1548 declaraba tener 60 años. México, 23 de diciembre de 1548. Archivo General de Indias (en adelante AGI), México, 96. Paso y Troncoso, Francisco del: Epistolario de Nueva España. 16 vols. México, 1939-1940. T. V, pág. 101.

8 Ibídem, pág. 257.

9 Falleció en 1489 en la toma de Baeza durante la guerra de Granada. Fernández del Castillo, Francisco: "Tres conquistadores...", pág. 253.

10 AGI, México, 96. México, 20 de enero de 1548. Paso y Troncoso, Francisco del: Epistolario..., T. V, pág. 69. 
sonas, arribando a Veracruz el 24 de febrero de 1521 en la nao "Santa María", como comisario de las Bulas de la Santa Cruzada — de ahí su apodo "el bulero"-,${ }^{11}$ junto con fray Pedro de Melgarejo de Urrea. ${ }^{12}$

Estuvo en la primera entrada de Texcoco, así como en la "conquista y toma de esta gran ciudad de México", participó en la entrada de la provincia de Pánuco, en las de las tierras de Yopilcingos y costas del mar del Sur hasta Zacatula; asimismo en Motín (donde había minas de Oro), Alina, Colima y Tecumán, obteniendo como recompensa escudo de armas. ${ }^{13}$

Tras la pacificación de aquellas nuevas tierras, regresó a España donde residió dos años, siendo llamado por la emperatriz para que le diese cuenta de los sucesos acaecidos. ${ }^{14}$ Aunque prefería quedarse en la corte, el emperador, en una audiencia concedida en Burgos (camino para las cortes de Monzón), le mandó volver a México y casarse ${ }^{15}$ ya que había ordenado al Consejo que se le concediese la encomienda de Chiautla y la gobernación de Jalisco y que "tuviese cargo de siempre le escrebir e informar...de lo que debiese ser informado, que a lo que screbiese se me daría entero crédito, por haber hallado todas mis relaciones tan verdaderas". ${ }^{16}$

En 1527 retornó a México $^{17}$ con el título de regidor para el primer pueblo que se fundara tras su llegada, de cuyo puesto no llegó a tomar posesión hasta más tarde, en que consiguió otro nombramiento para el Ayuntamiento de la capital, que presentó al Cabildo el 14 de abril de 1529, no siendo admitido hasta el 12 de mayo de $1531 .{ }^{18}$ Ostentó igualmente el cargo de secretario de gobernación. ${ }^{19}$

11 Recuerdo que de tiempos de la conquista guardaba de él Bernal Díaz del Castillo. Peña, José F. de la: Oligarquía y propiedad en Nueva España (1550-1624). México D.F., 1983, pág. 207.

12 Formaban parte, además del tesorero Julián de Alderete, "Antonio de Carbajal, Jerónimo Ruíz de la Mota e Juan Coronel, todos los demás, creo son muertos”. Fernández del Castillo, Francisco: "Tres conquistadores...”, págs. 253 y 318.

13 Ibídem, págs. 251, 253 y 318.

14 La visitó, estando también en la audiencia el futuro Felipe II; llevó "muchas cosas de las de acá", para que las viesen y se quedasen con algún presente. El príncipe tomó una cruz y su madre "un espejo de un águila grande de plata, con la cabeza e pies de oro”. AGI, México, 96. México, 10 de septiembre de 1545. Paso y Troncoso, Francisco del: Epistolario..., T. IV, pág. 228.

15 La Corona no deseaba que hubiera solteros en México, en general en toda América, tanto para poblarlos de españoles como para la mayor moralidad de las provincias, ordenándolo así en diversos decretos y reales cédulas. Fernández del Castillo, Francisco: “Tres conquistadores...”, pág. 320.

16 Este encargo de ser informante real lo tenía en gran estima y lo repite de continuo en varias de sus misivas. AGI, México, 96. México 10 de septiembre de 1545 y 15 de noviembre de 1547. Paso y Troncoso, Francisco del: Epistolario..., T. IV, págs. 172 y 228; T. V, pág. 54.

17 "Año del nascimiento de vuestra alteza". AGI, México, 96. México, 15 de noviembre de

1547. Paso y Troncoso, Francisco del: Epistolario..., T. V, pág. 53.

18 Fernández del Castillo, Francisco: "Tres conquistadores...”, pág. 319.

19 Ídem. 
Volvió de nuevo a España ${ }^{20}$ a dar cuenta en persona, "porque cartas no aprovechaban porque las tomaban todas....", ${ }^{21}$ de los disturbios existentes en México por los atropellos cometidos por el presidente de la primera Audiencia Nuño de Guzmán y algunos oidores "muy parciales al bando del factor Gonzalo de Salazar...especialmente contra los amigos e criados del marqués del Valle e sus parientes e allegados destruyéndolos a todos en cosas muy de hecho, e faciéndole extorsiones muy recias al dicho marqués", ${ }^{22}$ además de los disgustos y atentados contra el obispo Zumárraga. ${ }^{23}$

Llegó a México en 1538, y seis años después regresó de nuevo a la Península como procurador de la ciudad, en compañía de Peralmíndez Chirinos y Alonso de Villanueva, para tratar del repartimiento de tierras a los conquistadores, regresando sin haber terminado su comisión. ${ }^{24}$ No fue ese su último viaje a España ya que, años más tarde, decidió regresar de nuevo, esta vez acompañado de su hijo homónimo, que entonces tenía unos doce años, "para que me sirva y conozca a Su Majestad" ${ }^{25}$ y con el propósito de "pedir justicia", ${ }^{26}$ aunque temeroso, porque "ya iba sobre tres veces (la travesía) y pocos escapan de la tercera" ${ }^{27}$ Con esta desconfianza, otorgó su ya citada última voluntad ${ }^{28} \mathrm{y}$, efectivamente, "murió en la mar, en el navío que iba". ${ }^{29}$ El hijo, pues, llegó solo a España de donde regresó en 1551, a la edad de catorce años. ${ }^{30}$

20 Durante nueve meses intentó embarcar pero se lo impidieron "sacándome de los navíos". Compró incluso una nave, pero el día en que se dispuso a zarpar lo "prendieron e sacaron della y aquella noche quitaron un rumbo a la nao para que se fuese a fondo". AGI, México, 96. México, 15 de noviembre de 1547 y 20 de enero de 1548. Paso y Troncoso, Francisco del: Epistolario..., T. V, págs. 54 y 65.

21 Denunció que le habían interceptado tres, en las que indicaba las persecuciones que sufrió y la dificultad que tuvo para pasar a España. Fernández del Castillo, Francisco: “Tres conquistadores...”, pág. 319. Paso y Troncoso, Francisco del: Epistolario..., T. V, págs. 54 y 65. México, 25 de febrero de 1545 y T. IV, pág. 173

22 Se inician así las tensiones y enfrentamientos continuados de dos bandos rivales que culminarán en años posteriores en la supuesta sublevación del II marqués del Valle. Arenas Frutos, Isabel y Pérez Zarandieta, Purificación: "El primer criollismo en la conspiración de Martín Cortés” . Felipe II y el oficio de Rey: La fragua de un imperio. Román Gutiérrez, José; Martínez Ruíz, Enrique y González Rodríguez, Jaime (Coords.). Madrid, 2001, págs. 305-321.

23 AGI, México, 96 y S/F. Patronato Real, 184, n. ${ }^{\circ}$ 14. México, 25 de febrero de 1545. Paso y Troncoso, Francisco del: Epistolario..., Ts. IV, pág. 173 y XV, págs. 183-198.

24 Fernández del Castillo, Francisco: “Tres conquistadores...”, pág. 319.

25 Ibídem, págs. 242, 243 y 321.

26 Ídem.

27 AGI, México, 96. México, 25 de febrero de 1545. Paso y Troncoso, Francisco del: Epistolario..., T. IV, pág. 175.

28 Fernández del Castillo, Francisco: “Tres conquistadores...”, págs. 227-246.

29 Ibídem, pág. 224.

30 Ibídem, pág. 321. 
Este testamento nos revela una valiosa e interesante información en lo que a su vida familiar y cotidiana se refiere. Fue presentado por Pedro Hernández — su yerno, casado con su hija $\mathrm{Ana}^{31}$ —, cerrado, sellado y firmado por Cristóbal Rodríguez Bilbao, escribano, ante Andrés de Tapia, alcalde ordinario de la ciudad, y Pedro de Salazar, escribano público. Se presentaron como testigos Antonio de Turcios, secretario de la Real Audiencia, de más de treinta años; Diego Agundez, escribano, de más de veinticinco años y el dicho Cristóbal Rodríguez Bilbao, de la misma edad. ${ }^{32}$ Como albaceas nombró al licenciado Tejada, oidor de la Real Audiencia, a Antonio de Turcios, secretario de ella "porque yo lo tengo por hijo", a Juan Xaramillo, vecino de la ciudad, y a su esposa Mencía de Rivera. ${ }^{33}$

Entre sus "claúsulas espirituales", es decir las disposiciones que hizo respecto a sus honras fúnebres, número de misas, mandas pías, etc., muy numerosas y detalladas, ${ }^{34}$ como era habitual, pedía ser enterrado en la sacristía grande del monasterio de San Agustín..$^{35}$ Indicaba ser hermano de las cofradías y hermandades "del hospital de La Concepción desta ciudad y del Santísimo Sacramento y Caridad y de los Ángeles y Santa Bárbara y Nuestra Señora del Rosario y de las Ánimas del Purgatorio y del Nombre de Jesús". ${ }^{36}$

En México tuvo su domicilio en la calle de los Oidores, frente a la cárcel. ${ }^{37}$ La mayoría de los conquistadores españoles tenía la costumbre de compartir vivienda y comida, aparte de su familia, con gran cantidad de parientes y allegados, además de un alto número de esclavos, tanto indígenas, como negros, como es el caso que nos ocupa, ya que en muchas de sus epístolas hace continua alusión a sus grandes gastos debidos a "casa abierta para cuantos la quieren, mujer española hijadalgo, diez hijos e hijas, larga familia de gente doméstica". ${ }^{38}$ Entre éstos últimos, los sirvientes, indi-

31 Ver nota 45.

32 Fernández del Castillo, Francisco: “Tres conquistadores...", págs. 224-226.

33 Ibídem, pág. 244.

34 Ibídem, págs. 228-233.

35 Allí fueron enterrados los miembros de esta familia, por ser patronos de ella, hasta que fue nacionalizada la iglesia y convento, en virtud de las Leyes de Reforma de la segunda mitad del siglo XIX. Ibídem, pág. 228.

36 Ibídem, pág. 229.

37 Sin duda fue ese el segundo lugar que ocupó la cárcel, pues antes estuvo en la calle de Tacuba. Ibídem, págs. 247 y 319.

38 AGI, México, 96. México, 25 de febrero de 1545. Paso y Troncoso, Francisco del: Epistolario..., T. IV, pág. 175. Fernández del Castillo, Francisco: "Tres conquistadores...”, págs. 239 y 240. Valero de García Lascurain, Ana Rita: La ciudad de México-Tenochtitlan. Su primera traza, 1524-1534. México, 1991, pág. 100. 
caba en su testamento que los tenía "por compra que dellos he hecho a diversas personas", y pedía que no fueran vendidos, sino que sirvieran posteriormente a sus hijos. Entre los que vivían en su residencia, comprados antes del último matrimonio, se contaban: Francisco, indio, sastre, y Elvira, también india; casados y con hijos. Tenía además cuatro negros y dos negras: Juanes, Francisco, Cristóbal, Hernando, Isabel y Catalina ${ }^{39}$ más "dos hombres de España a quien doy salario". ${ }^{40}$

Con respecto a su extensa progenie, fue debida a tres matrimonios:41

- El primero, el 24 de noviembre de 1532, con Elvira Álvarez de Mendoza, hija de Alonso Durán de Mendoza, natural de Trujillo o Medellín. Fruto de esta unión, nacieron tres hijos. Un varón que falleció niño y dos hembras: María de la Concepción y Ana López ó Ana de Mendoza.

- El 4 de septiembre de 1536 se volvió a casar con Catalina Álvarez de Cabrera, natural de Badajoz, hija de Juan Zapata y Catalina Núñez. Estuvo casado con ella diez meses y once días, dejándole un hijo, al que se le conoció como "el Mozo", para diferenciarlo de su padre - "el Viejo"-

- Por tercera vez, el 17 de junio, lunes siguiente de la Trinidad, de 1538, en la iglesia de la Santa Veracruz contrajo nuevo matrimonio con doña Mencía de Rivera, viuda. ${ }^{42}$ Tuvo de esta tercera unión a Bernardina, Juan, Pedro, Luis, Jerónima, Isabel y Beatriz. Llaman en este caso la atención dos cartas de $1547^{43}$ y $1548,{ }^{44}$ sobre su descendencia, "en especial de las mujeres". En la primera, indicaba tener "seis doncellas e la mujer para parir"; en la segunda, especificaba en sendas ocasiones, que eran $11-7$ hembras y 4 varones-, aunque en el testa-

39 En dicho testamento indicaba que la llevaba a "este viaje que quiero hacer a España". Fernández del Castillo, Francisco: "Tres conquistadores...”, págs. 239 y 240.

40 Ibídem, pág. 256.

41 Ibídem, pág. 232.

42 Su primer matrimonio debió de haberlo realizado a muy temprana edad, ya que en su testamento Jerónimo López aún la sigue calificando como "moza" en "edad de poderse casar...después de mi muerte...porque menor hierro (yerro) que puede hacer e más acertado es casarse, por ques una barrera segura de donde se acoce a él el demonio y se asegura la honra de las buenas mujeres...”. Ibídem, págs. 233 y 234.

43 AGI, México, 96. México, 15 de noviembre de 1547. Paso y Troncoso, Francisco del: Epistolario..., T. V, pág. 47.

44 En ésta lo especificaba en sendas ocasiones. Ibídem, México, 20 de enero de 1548 y págs. 77 y 78 . 
mento realizado al año posterior (1549) citaba sólo 10 — 6 hijas y 4 hijos-, como hemos comprobado. Debió pues, fallecer una de ellas en ese intervalo de tiempo.

Una de sus hijas mayores, Ana López ó Mendoza, se casó, con unos catorce o quince años, con Pedro Hernández Botello. ${ }^{45} \mathrm{Al}$ enviudar, probablemente sin hijos, se volvió a casar con Diego de Villa Padierna.

Otra parece ser que sufrió un gran desengaño amoroso, contando apenas quince años. Fue requerida en amores por el futuro cronista Baltasar Dorantes de Carranza, que sólo tenía uno o dos años más; éste, valiéndose de la intimidad y acaso del parentesco que le unía a la familia, pretendió a una de las hijas, casándose con ella "por presente"; ${ }^{46} \sin$ embargo, pronto la abandonó, pretendiendo volver a unirse con otra. Fue denunciado y se descubrió que ya estaba casado con anterioridad con doña Mariana Bravo Lagunas, hija del conquistador don Juan Bravo de Laguna. La hija de Jerónimo López, viendo rotas sus ilusiones, entró en un convento donde profesó. Dorantes escapó a su encomienda de Acala, y por fin, acaso en virtud de las influencias familiares, pagó una multa y quedó en paz. ${ }^{47}$

Se revela la severa educación que deben recibir esos varones: "industriados en las cosas del servicio de Dios"; que aprendan a "leer y escribir y contar...de edad de hasta diez u once años...hasta que sean buenos gramáticos, en lo qual gasten sus tres ó quatro años"; siendo de edad de quince años "sepan de ellos el estado que quisieren seguir y si alguno quisiere de su buena voluntad ser clérigo e quisiere más estudio...que se le de para el dicho efe(c)to y llegado a edad se ordene e cante misa e si quisiere ser religioso, fraile de alguna de las órdenes de esta ciudad, lo sea con mi bendición y si quisiere ser casado, sirva a su madre y hermanas hasta que tenga edad cumplida que pase de veinte e cinco años e que entonces, los

45 Esta pareja igualmente se quedó viviendo en la casa familiar. Su yerno se hizo cargo de la hacienda cuando él falleció. Fernández del Castillo, Francisco: "Tres conquistadores...”, pág. 242.

46 En aquellos tiempos no había mucho rigor para los casamientos; bastaba que se dieran "las manos de presente" delante de dos testigos, prometiéndose por esposos, a reserva de velarse después ante un sacerdote, al que deberían de repetir su juramento para que el sacramento fuera válido. Ibídem, pág. 321.

47 Estos abusos del matrimonio de "las manos de presente" dieron lugar a que la Iglesia prohibiera esa práctica, obligando a la publicación e información de amonestaciones y se persiguió muy duramente la bigamia. Seed Patricia: Amar, honrar y obedecer en el México colonial. Conflictos en torno a la elección matrimonial, 1574-1821. México D.F., 1991, Parte I y en especial "El honor", págs. 87-103. 
dichos mis albaceas e tutores, le busquen mujer virtuosa e de buenos padres e lo casen e le den la parte que le pertenecerá de mis bienes y en tal caso, se entienda casar primero a mis hijas mayores ${ }^{48}$ y no antes a ninguno de los hijos". El vestido de éstos últimos, mientras estuviesen bajo la tutela de su madre, tenía que ser "muy honesto y de paño negro y gorras de paño y jubones de lienzo e camisas de Ruán...que no vistan seda de ninguna calidad, de ribete, ni tira, ni pasamano, ni tafetanes en calzas ni en otra cosa". Igualmente y con respecto a las hijas: "que desde diez años arriba, vayan los domingos e fiestas a misa con su madre"; se las enseñase "a coser, labrar e todas las demás cosas que conviene que sepan las mujeres buenas para regir su casa e servir a Dios e a sus maridos"; "que no pongan sedas ni se pongan estampas, ni cabelleras, ni lazos, ni afeites en sus rostros, ni zarcillos, ni cosa deshonesta a que el mundo convida con sus engaños". Habían de rezar "todas las noches después de la cena, diciendo la doctrina cristiana a todos los de mi casa". ${ }^{49}$

También da cuenta de su delicada salud al padecer "enfermedades de gota y otras de vejez quebrantada" ${ }^{50}$ y haber perdido incluso un ojo en su segundo viaje a España. ${ }^{51}$

Aparte de las posesiones ya citadas, donde se contaban un buen número de cabezas de ganado, en el inventario que se realizó tras su fallecimiento, se indica una heredad de tierras detrás de Chapultepec, al lado de otra de Ruy González, donde reunía también novillos, puercos, ovejas... Además de mencionar la cantidad de 1.509 pesos de oro común en tostones (cantidad nada despreciable), más algunas joyas y menaje de la casa. ${ }^{52}$ Sería interesante realizar un estudio comparativo con otros bienes de difuntos de la época, para analizar el poder adquisitivo del momento, la forma de vida, costumbres usuales...etc.

48 Para ayuda en sus casamientos “porque son mujeres y tienen más necesidad de ser más temprano favorecidas", les dejó a cada una cuatrocientos mil maravedíes. Ibídem, págs. 241-244.

49 Ibídem, págs. 236- 238. La educación de las niñas y jóvenes hispanas y por extensión en el Nuevo Mundo, se encaminó durante siglos a procurar mujeres adultas que concordasen con el módulo que los moralistas habían acuñado. El conocimiento de la doctrina cristiana, primero, y de las labores hogareñas, después, eran los elementos fundamentales de ella. Garrido, Elisa (Edit.); Folguera, Pilar; Ortega, Margarita y Segura, Cristina: Historia de las mujeres en España. Madrid, 1997. Parte IV: Las mujeres en la España Moderna, págs. 247-344. VV.AA: Textos para la historia de las mujeres en España. Madrid, 1994, pág. 242.

50 AGI, México, 96. México, 15 de noviembre de 1547 y 20 de enero de 1548. Paso y Troncoso, Francisco del: Epistolario..., T. V, págs. 47 y 68.

51 Ibídem. 25 de febrero de 1545 y T. IV, pág. 173.

52 Fernández del Castillo, Francisco: "Tres conquistadores...”, págs. 247-250. 


\section{Continuas reivindicaciones}

De todos es conocida la dilación en la resolución de los asuntos indianos y cómo muchas medidas y determinaciones a aplicar en el Nuevo Mundo, tardaron años en atenderse, o nunca llegaron a implantarse, por circunstancias diversas. Quizás por ello, las peticiones y memoriales públicos y privados procedentes de tierras americanas se multiplican y apilan, repitiéndose una y otra vez las mismas solicitudes esperando la tan ansiada respuesta. Lo mismo ocurrió con nuestro biografiado. En sus escritos las exigencias son muchas, algunas reiterativas, de las que citaremos a continuación tan sólo las más relevantes:

En primer lugar, siempre destaca la figura del conquistador, en contraposición a la de los pobladores y colonizadores, que aún habiendo llegado con posterioridad "gozan de la tierra y de los favores, frutos e rentas della, los que la ganamos morimos de hambre...mendigando, que no les alcanza favor alguno de tanto cuanto hay...y se les podría dar y hacer", ${ }^{33}$ siendo muy injusto que "quedemos para servir a los que agora han venido", viéndolos "a todos éstos ricos e a mí pobre" ${ }^{54}$ Su resentimiento se centraba, lógicamente, en los premios que le habían sido otorgados y su poca importancia. Como anteriormente comentamos, desde su establecimiento en la ciudad de México, el rey le concedió la encomienda de Chiautla y la gobernación de Jalisco. ${ }^{55}$ De la primera, jamás llegó a tomar posesión ${ }^{56}$ y aunque en 1543 se le encomendó el pueblo de Axacuba, ${ }^{57}$ lo consideró una injusticia, al ser este último "un poblezuelo muy pobre e miserable que valdrá en cada año hasta cuarenta e cinco o cincuenta mil maravedíes de renta e no más", ${ }^{58}$ mientras otras personas "tienen los repartimientos doblados, e muy doblados y otros, no tienen de comer o mueren de hambre". ${ }^{59}$ En cuanto a la gobernación de Jalisco, veinte años más tarde de su conce-

53 AGI, México, 96. México, 15 de noviembre de 1547. Paso y Troncoso, Francisco del: Epistolario..., T. V, págs. 48 y 54.

54 Ibídem, México, 20 de enero de 1548 y pág. 76.

55 En una de estas cartas llega a citar en seis ocasiones la injusticia que se cometía en no concederle esta encomienda.

56 En 1520, fue encomendada a Diego de Ordás, luego a Alonso de Grado, que murió en 1527. Con la segunda Audiencia, pasó a depender de la Corona. Gerhard, Peter: A guide to the historical geography of New Spain. Cambridge, 1972, págs. 108 y 109.

57 Pasó tras su muerte, en 1550, a ser asignado a su hijo “el Mozo”. Ibídem, pág. 296.

58 AGI, México, 95. México, 20 de enero de 1543. Paso y Troncoso, Francisco del: Epistolario..., T. IV, pág. 50.

59 Ibídem, México, 6 de febrero de 1541 y pág. 19. 
sión por el rey -1547—, aún se hallaba solicitando su adjudicación al estar vacante, indicando que él participó "en la descobrir e conquistar", gastando en ella parte de su hacienda ${ }^{60}$ pero tampoco la ocuparía. Se quejó hasta el final de sus días de "los grandes agravios que se me han hecho y cómo no se ha complido conmigo alguna merced". ${ }^{61}$

Debido a esta situación de necesidad en la que se hallaba, sus hijos llevaban "mantas de la tierra...retraidos a un rincón", mientras que los de los pobladores van "vestidos de seda y oro", y sus hijas "desnudas, e que por ser pobres no haya quien me las pida (en matrimonio), ni aún quien las tome aunque las dé de balde". ${ }^{62}$ En ese mismo año - 1547—, afirmaba que sus hijas contaban de 14 años "para abajo" y sus hijos "el mayor de 10". ${ }^{63}$

\section{Sus tendencias protoarbitristas}

\section{Riqueza informativa}

La orden real recibida por Jerónimo López, y ya comentada, de "escrebir e informar" ${ }^{4}$ fue cumplida con largueza ya que nos proporciona una amplia secuencia epistolar con datos de primera mano en esos iniciales momentos del establecimiento español en aquellas provincias. Notificó sobre todos los asuntos, problemas y personajes que consideró dignos de mención, tanto, y en forma tan precisa, que en ciertos momentos su prolija escritura debió resultar molesta, al mostrarse algunos individuos recelosos contra él, ante "la sospecha que...dellos informaba mal a vuestra majestad". ${ }^{65}$

60 AGI, México, 96. México, 15 de noviembre de 1547. Paso y Troncoso, Francisco del: Epistolario..., T. V, pág. 55.

61 Ibídem, 23 de diciembre de 1548 y pág. 102.

62 Solicita que a los que se casasen con ellas "les favorezcan y les provean de cargos e corregimientos”. Ibídem, México, 15 de noviembre de 1547 y págs. 47-55. Ya por estas fechas se van haciendo patentes las quejas emitidas por Gonzalo Gómez de Cervantes cuando indicaba que "a causa de haber subido tanto las dotes (se refiere a las del matrimonio) no hay hombre principal que pueda casar hija, y así hay tantos monasterios llenos de hijas de caballeros ciudadanos...". Gómez de Cervantes, Gonzalo: La vida económica y social de la Nueva España al finalizar el siglo XVI. México, 1944, pág. 125.

63 Fernández del Castillo, Francisco: “Tres conquistadores...”, pág. 256.

64 Ver nota 16.

65 AGI, México, 96. México, 20 de enero de 1548. Paso y Troncoso, Francisco del: Epistolario..., T. V, pág. 65. 
Las referencias más destacables en sus escritos son:

Con respecto a la población, indicará la "mucha disminución de gente (española)" ${ }^{\prime 66}$ que, buscando nuevos horizontes y mayores posibilidades de vida, "se fueron e van cada día por muchas partes, especialmente a la provincia de Guatimala...para desde allí pasar al Perú", mientras que los naturales "son muchos e aumentan de cada día en grand número", corriéndose un grave riesgo, al ser "gente muy belicosa" pudiendo tener el "deseo de verse como en su principio". ${ }^{67}$ Sin embargo, la situación pronto cambió a consecuencia de una importante epidemia ${ }^{68}$ que asoló "en 10 leguas a la redonda (a la ciudad) de México", afectando a las zonas frías, "que en la caliente no ha tocado", hasta fallecer en siete meses más de 400.000 personas, entre ellas "todo el servicio de la gente doméstica desclavos negros y blancos". Puesto que de su casa murieron 22 personas y "los 17 esclavos negros y blancos", solicitó la merced de poder importar "cincuenta negros e negras horros de todos derechos...para ayuda a rehacer el servicio de casa". ${ }^{69}$

En cuanto a la organización administrativa, conocemos los problemas surgidos con los repartos de encomiendas, que en teoría se realizaron para "cada uno segund sus servicios" en las personas de Bernardino Vázquez de Tapia, Andrés de Tapia, Alonso de Ávila, Gil González de Ávila...etc. ${ }^{70}$ Vinculado a este tema, notifica la venida del presidente y oidores de la primera Audiencia y el gran desorden que ésta supuso. ${ }^{71}$

Igualmente comunica la llegada del visitador Tello de Sandoval, el "buen rescibimiento questa cibdad le hizo" y cómo habló con él en varias ocasiones, comentándole diferentes aspectos, al ser estas provincias "muy diferente de las cosas Despaña", reconociendo el mismo licenciado que era la persona idónea, al conocer "más de las cosas de la tierra que no los recién venidos". ${ }^{72}$

66 En tan sólo ocho días salieron más de cien hombres.

67 AGI, México, 95. México, 10 de febrero de 1534. Paso y Troncoso, Francisco del: Epistolario..., T. III, págs. 133 y 134.

68 Durante la época española fueron frecuentes en el territorio de la Nueva España grandes pandemias que diezmaron repetidas veces la población indígena. Chávez, Ignacio: México en la cultura médica. México, 1947, pág. 49.

69 AGI, México, 96. México, 10 de septiembre y 15 de noviembre de 1545 y 1547 . Paso y Troncoso, Francisco del: Epistolario..., Ts. IV y V, págs. 50 y 232.

70 Ibídem, México, 1 de marzo de 1547, T. V, pág. 7.

71 AGI, México, 95 y 96. México, 10 y 25 de febrero de 1534 y 1545 . Paso y Troncoso, Francisco del: Epistolario..., Ts. III y IV, págs. 132 y 173. Ruíz Medrano, Ethelia: Gobierno y sociedad en Nueva España: Segunda Audiencia y Antonio de Mendoza. México, 1991.

72 AGI, México, 96. México, 25 de febrero y 1 de marzo de 1545 y 1547. Paso y Troncoso, Francisco del: Epistolario..., Ts. IV y V, págs. 152 y 153. 
En lo que se refiere a la Iglesia, realiza una dura crítica de sus componentes, mostrándose anticlerical al asegurar que los religiosos no padecen necesidad "porque todos están ricos e prósperos", y que aun siendo algunos "santos y buenos", hay muchos frailes soberbios y necios. ${ }^{73}$ Hay que situar esta opinión en los años de tensiones entre las órdenes religiosas y los conquistadores, que veían cómo se discutían sus premios e incluso perdían sus encomiendas tras las Leyes Nuevas, pese a la reforma de éstas en Malinas (1546).

Interesante también el apartado que podríamos denominar nuevas fronteras, donde se cita la exploración e incorporación de otras provincias (Florida, ${ }^{74}$ Campeche, Pánuco ${ }^{75} \ldots$ ), indicando que antes de salir a tierras como el Perú, hay que pacificar México "porque no es justo que la Nueva España quede levantada". ${ }^{76}$

\section{Medidas a seguir}

"Este negocio (la organización de la Nueva España) es tan arduo y de tan gran calidad que yo no se decir ni ponderar las grandes calidades que tiene porque no es de uno sino de muchos, no de muchos, sino de muy muchos, no de una ciudad, sino de muchas, que se han de hacer no de un reino sino de más, no de los presentes que habitan en él sino de los absentes, no de los nacidos, sino de los por nacer, no de los españoles sólo el bien, sino de los naturales, por la perpetuidad e quietud e reposo dellos,... No es esto para diez ni veinte años sino para siempre". ${ }^{77}$

Este párrafo de 1548, entresacado de una de sus misivas finales — siendo ya buen conocedor de aquella tierra por sus muchos años de estancia en la Nueva España-, creemos que es lo suficientemente ejemplificador de su carácter y tendencia y donde se reflejan con claridad sus largas miras arbitristas con respecto a aquellas provincias. Llama la atención el hecho de visionar y tratar de neutralizar esa realidad próxima, donde las dos culturas

73 Ibídem, México, 1 de marzo de 1547, T. V, págs. 15 y 21.

74 Arenas Frutos, Isabel: "Intentos colonizadores en Florida a mediados del siglo XVI". Actas del Congreso de Historia del Descubrimiento (1492-1556). 4 vols. Madrid, 1992. T. III, págs. 11-25.

75 Chipman, Donald E.: Nuño de Guzman and the Province of Panuco in New Spain, 15181533. Glendale, Cal., 1967. Sarabia Viejo, M. ${ }^{a}$ Justina: "La esclavitud indígena en la gobernación de Pánuco". Atti del XL Congresso Internazionale degli Americanisti. 3 vols. Roma-Génova, 1972. T. III, págs. 423-437.

76 AGI, México, 96, México, 1 de marzo y 15 de noviembre de 1547. Paso y Troncoso, Francisco del: Epistolario..., T. V, pág. 21.

77 Ibídem, México, 20 de enero de 1548, T. V , págs. 70 y 71. 
más representativas —indígena y española — tendrían que luchar conjuntamente para conseguir el bien común de esa futura nación mexicana.

La inclusión de Jerónimo López dentro de esa tendencia protoarbitrista, viene motivada por la idea que siempre mantuvo de "escrebir de los defetos e daños de la tierra...dando los remedios convenientes para ello", repitiendo esa palabra que subrayamos, _remedios_-, en muchos de sus escritos, al ser además característica fundamental de los seguidores de esa escuela, como ya comentamos. Tanto es así que, aparte de señalar diferentes enmiendas sobre los asuntos intercalados en sus cartas, decidió redactar un amplio memorial, pormenorizando estas soluciones en un extenso programa con un total de 21 puntos: $^{78}$

1) Que se realizasen encomiendas perpetuas, porque "en esto está toda la quietud e sosiego de la tierra", ya que así los encomenderos tratarían de "beneficiar e sustentar e aprovechar", a los indígenas, procurando "hacerlos xriptianos e instruirlos en la fe, lo cual no se hace", sino que los obligaban a trabajar "muy demasiado...y échanlos a perder".

2) Que a los visitadores, alguaciles, escribanos y "lenguas o nahuatatos" que les acompañaron, se les hiciera juicio de residencia "y se les tome por muy estrecha cuenta porque han robado mucho...".

3) Que los naturales fueran muy favorecidos "para que tengan lugar de ocuparse en las cosas de la fe", remediados con justicia en las vejaciones que les han sido hechas y que "lo que les han tomado e robado se les restituya".

4) Que a los anteriores les han sido quitadas el agua, haciendas, tierras y sitios, despojados especialmente por los dichos presidente y oidores de la Audiencia, los cuales se habían construido "molinos e huertas e casas de placer...todo a costa de los naturales e en gran daño e perjuicio suyo". Pedía que todo les fuera restituido, siendo pagados por lo que habían trabajado.

5) Que la ermita de San Lázaro, que habían mandado construir los conquistadores y vecinos españoles "habrá más de seis o siete años", a costa de los indios, como a un cuarto de legua de la ciudad de México, "en la cual muchas veces se había celebrado culto divino e ido a ella con procesiones", fue derruida por Nuño de Guzmán, mandando "edi-

78 Memorial que dio por extenso Jerónimo López, conquistador de Nueva España, sobre el gobierno de aquel reino. AGI, Patronato Real, 184, n. ${ }^{\circ}$ 14. S/F. Paso y Troncoso, Francisco del: Epistolario..., T. XV, págs. 183-198. 
ficar una casa de placer muy grande e populosa con sus corredores e ventanas e torre muy bien obrada e fizo cercar de muralla un grande sitio de tierra de compás de cuatro huertas para hacer vergel en el cual edeficaba e mandaba edeficar estanques de agua de argamasa e cenaderos". Esto provocó gran indignación, ya que los naturales afirmaban que era "casa de borrachería", al ir allí dicho presidente "con mujeres e otras personas a hacer banquetes". Solicitaba la reedificación de la ermita para ser usada como tal, dedicando una parte de ella a iglesia y la otra para los pobres como hospital, teniendo así los indígenas "por bien gastado lo que han gastado en la dicha obra".

6) Que a los oficiales reales, como ya gozaban de un salario "de quinientos o seiscientos mil maravedíes cada uno", se les quitasen indígenas y repartimientos de "veinte o treinta mil vasallos", que les suponía de renta otros diez mil pesos de oro, porque "roban a los indios e los destruyen". Él señalaría a cuatro personas "que fagan muy mejor los dichos cargos e con más fidelidad e deligencia porque ellos residirán personalmente a las fundiciones e a lo que fuese nescesario, lo cual ellos no facen, antes ponen mozos e personas que roban...”. Estos cuatro designados, "no llevarían salario ninguno...sino por ser favorescidos e aprovechados en sus repartimientos...lo cual se hará con la cuarta parte de los indios que ellos tienen".

7) Que los naturales repartidos por el presidente y oidores (de la primera Audiencia) a parientes y criados "nuevamente venidos a la tierra", fueran restituidos "a las personas a quien ellos los han quitado...pues los dieron e tomaron para sí contra el mandamiento de vuestra majestad".

8) Que los conquistadores resultasen "muy favorescidos e aprovechados pues derramaron su sangre en la pacificación de la tierra..., e fueron en ponella debajo del yugo de vuestra majestad y así serán siempre pasando adelante en aumento de la Santa Fe Católica".

9) Que fuera guardada y cumplida la real cédula para que no pasasen a Indias los prohibidos, puesto que sería "en gran perjuicio de la tierra e deservicio de su majestad e gran peligro".

10) Que los casados vinieran de la Península con sus mujeres o enviasen por ellas.

11) Que el que fuera a poblar la Nueva España no pagase almojarifazgo de su casa y de las cosas que llevase, excepto si eran mercancías para vender "porque la tierra se pueble mejor". 
12) Que los conquistadores pudieran llevar todo lo necesario para proveer su casa y hacienda sin almojarifazgo,$^{79}$ con tanto que no fueran mercadurías para vender... porque hay mercaderes conquistadores".

13) Que se designase un protector de indios, "para que les pida su justicia que sea persona celosa del servicio de su majestad al cual... provea dándole poder bastante e ansí los indios que han sido agraviados... serán restituidos e remediados con justicia".

14) Que fuesen revocadas las penas sobre juegos, "porque ha habido día en dos sentencias sobre juego de condenación de veinte e dos mil e seiscientos pesos de oro sin otros muchos que han sido condenados desta manera".

15) Que las órdenes emitidas sobre el marcar a los esclavos fueran revisadas, porque "se ha tenido mucho desorden". Solicitaba "quel fierro tenga persona celoso del servicio de Dios y de vuestra majestad".

16) Que el presidente y oidores no se enterasen de las nuevas elecciones de estos mismos cargos "que agora van" y no les diese tiempo a ocultar los desmanes cometidos en la provincia de Pánuco adonde Nuño de Guzmán era gobernador, porque "de lo que tienen mal llevado se pueda restituir a los dagnificados (sic) por ellos".

17) Que se tomase residencia a los visitadores, alguaciles, escribanos y "lenguas o naguatatos" que les acompañasen, "que entre éstos se hallarán grandes robos e se descobrirán cosas que no se saben porque los indios darán relación de todo lo que les han robado fasta hoy porque lo tendrán asentado e pintado en sus libros e pinturas...que se les de crédito a esto". ${ }^{80}$

18) Que se tomasen medidas contra un indígena "lengua o nahuatato" llamado García del Pilar quien, junto al presidente, oidores y el factor Gonzalo de Salazar, "han llevado e robado más de diez quintales de plata sin otras muchas cosas" a los indígenas de Michoacán.

19) Que a Nuño de Guzmán, además del juicio de residencia como presidente, se le hiciera igualmente del cargo de gobernador de la provincia de Pánuco, "porque son cosas excesivas las que allá dicen que han pasado especialmente el destruimiento que ha fecho de la tierra en el sacar de los naturales con codicia...e aún faciéndolos esclavos (a) muchos no siéndolo". Así se intentaría remediar y restaurar lo ocurri-

79 Reitera la petición anterior.

80 Es repetición del punto 2. 
do en aquel territorio, nombrándose a "otra persona que guarde los mandamientos...y mire por el bien e sustento della".

20) Que por ningún puerto pudieran sacarse naturales, claramente vinculado a los abusos de Nuño de Guzmán y sus auxiliares, ya señalados.

21) Que en los procesos realizados sobre juegos y confiscación de los naturales donde no se hubiesen otorgado apelaciones, se remitiesen a la corte, para que el rey tuviera noticia de ello.

\section{Una familia en alza}

Analizando su testamento, todos los bienes de la familia López consistían en una encomienda, unas pocas tierras y muchos hijos. Hay que reconocer que por esos años aún no se contaban entre las ricas familias allende el Atlántico, circunstancia que irá cambiando con el paso de los años. El mayor de ellos, "el Mozo", contaba, como ya hemos indicado, tan sólo doce años al morir su padre en 1549. Desde este momento hasta el de su segundo matrimonio, en 1567, con Ana Carrillo de Peralta, sobrina de don Gastón de Peralta, marqués de Falces y virrey de México, ${ }^{81}$ los bienes de éste debieron experimentar un considerable aumento, ya que es difícil que en tierra de tan importantes fortunas como la mexicana, el virrey fuese a casar a alguien de su más inmediata parentela con quien no correspondiese. En éste, como en la mayoría de los casos, es complicado rastrear convenientemente las causas y modos que permitieron la creación de la fortuna, aunque sí podemos conocer su ritmo de crecimiento en lo que a adquisición de inmuebles se refiere.

Con la boda de Jerónimo López "el Mozo" se inició una amplia alianza de parentescos de la alta burocracia colonial, respondiendo a esa estrategia económica y social tan típica del mundo novohispano. ${ }^{82} \mathrm{~A}$ partir de ésta, casi sin excepción por vía de hembra, emparentaron con los condes de Santiago, Ovando, Rivadeneyra y con los Cervantes. Como consecuencia de esta bien llevada trama familiar, al cabo de cuatro generaciones quedaron unidos los marquesados de Salinas y Salvatierra y el condado de Santiago Calimaya. ${ }^{83}$

81 Fernández del Castillo, Francisco: "Tres conquistadores...”, pág. 322.

82 Artís Espriu, Gloria: Familia, riqueza y poder. Un estudio genealógico de la oligarquía novohispana. México, 1994, pág. 65 y Anexo (Genealogía 2).

83 Peña, Jose F. de la: Oligarquía y propiedad..., págs. 207-209. 
Tras tantas quejas y peticiones emitidas por Jerónimo López, sobre la acuciante necesidad que sufría su progenie, con sus hijos llevando "mantas de la tierra... (y) retraidos a un rincón", y sus hijas "desnudas...", sin haber nadie que "las pida (en matrimonio), ni aún quien las tome aunque las dé de balde" ${ }^{84}$ le hubiera resultado altamente satisfactorio comprobar cómo, con esa endogamia de grupo tan característica, que apuntábamos en las altas estirpes mexicanas ${ }^{85}$ sus descendientes se habían convertido, en relativamente poco tiempo, en miembros integrantes los más ricos, principales y codiciados linajes novohispanos.

84 Ver nota 62.

85 Arenas Frutos, Isabel: "Élite mexicana y criollismo eclesiástico (Siglo XVII)". X Congreso de la Asociación de Historiadores Americanistas Europeos (AHILA). Las transformaciones hacia la sociedad en América Latina: causas y condiciones en la economía, la política y las mentalidades. Coordinación de M. Zeuske con la colaboración de H. Pietschmann y H.J. Köning. C-D Rom editado en Leipzig-Köln (Alemania), 1996, Eje I, Simposio 4. 